Rhode Island College

Digital Commons @ RIC

Master's Theses, Dissertations, Graduate

Master's Theses, Dissertations, Graduate Research and Major Papers Overview

Research and Major Papers

$1-1-2013$

\title{
Nurses' Attitudes towards Drug-Seekers in the Emergency Room
}

Megan E. Gernt

Rhode Island College

Follow this and additional works at: https://digitalcommons.ric.edu/etd

Part of the Other Nursing Commons, Other Public Health Commons, and the Public Health and Community Nursing Commons

\section{Recommended Citation}

Gernt, Megan E., "Nurses' Attitudes towards Drug-Seekers in the Emergency Room" (2013). Master's Theses, Dissertations, Graduate Research and Major Papers Overview. 236.

https://digitalcommons.ric.edu/etd/236

This Major Paper is brought to you for free and open access by the Master's Theses, Dissertations, Graduate Research and Major Papers at Digital Commons @ RIC. It has been accepted for inclusion in Master's Theses, Dissertations, Graduate Research and Major Papers Overview by an authorized administrator of Digital Commons @ RIC. For more information, please contact digitalcommons@ric.edu. 
NURSES' ATTITUDES

\title{
NURSES' ATTITUDES TOWARD DRUG SEEKERS IN THE EMERGENCY ROOM
}

\author{
by \\ Megan Gernt \\ A Major Paper Submitted in Partial Fulfillment \\ of the Requirements for the Degree of \\ Master of Science in Nursing \\ in \\ the School of Nursing \\ Rhode Island College
}

2013 


\begin{abstract}
Emergency department patients often present with a chief complaint of pain. There is a unique population of patients who present with this chief complaint in an effort to obtain narcotics for non-medical use. This population is often referred to as drug-seekers and there is little information available to define what exactly nurses mean when they use this term. This study utilized a descriptive survey design to gain a better understanding of nurses' use of the term drug-seeker. Respondents agreed on a variety of behaviors that lead them to identify patients as drug-seeking and expressed a frustration with this population of patients. Many respondents identified a lack of clear policies and education around this population as a challenge. By understanding how nurses use the term drug-seeking, and developing an understanding what some of their concerns are regarding this population, the opportunity presents itself for the development of educational programs in order to train health care providers to best care for this challenging population. Additionally, the opportunity exists for policy development and implementation around this population in order to provide safe, comprehensive, and satisfactory care.
\end{abstract}


NURSES' ATTITUDES

Table of Contents

Table of Contents.......................................................

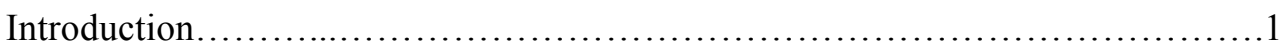

Literature Review ............................................................

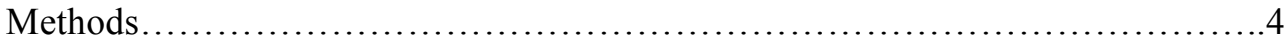

Results..............................................................6



Limitations............................................................... 11

Implications for Advanced Nursing Practice and Conclusions....................12

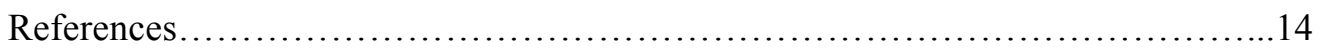


NURSES' ATTITUDES

This paper was prepared as a manuscript submission, following the guidelines as required by The Journal of Emergency Nursing. 
NURSES' ATTITUDES

\section{Introduction}

In 2007, pain was the chief complaint for the majority of the 118.6 million Emergency Department (ED) visits, with abdominal pain and chest pain being the two most common complaints. ${ }^{1}$ In this same year, four narcotic pain medications were amongst the top ten drugs prescribed to ED patients. Non-narcotic analgesics accounted for three of the top ten drugs prescribed in that year. Analgesics accounted for $36.7 \%$ of all drugs prescribed in the emergency department. This is more than any other class of medication prescribed. It is nearly impossible to quantify how many of these visits for pain and these prescriptions for analgesics are necessary, and how many are instead misprescribed and are being misused. In 2008, the Centers for Disease Control (CDC) attempted to quantify this number and reported that there were 305,900 visits to emergency departments across the country to obtain narcotics for nonmedical uses. ${ }^{2}$ When considering that 16 million Americans reported to have used prescription drugs illicitly in 2009, clinicians must wonder if the number reported by the CDC is grossly inaccurate and if so, what the reasons for this inaccuracy are. ${ }^{3}$ Likely a major reason is underreporting: do clinicians report that patients are seeking emergency care for the sole purpose of obtaining narcotics in the absence of a true medical condition that is causing pain?

It is mandated that pain must be appropriately assessed on an ongoing basis while patients are in a facility accredited by The Joint Commission. ${ }^{4}$ Nurses are the care givers primarily responsible for this ongoing assessment. Many health care workers are familiar with the notion that pain is whatever the patient says pain is, and have been firmly instructed that they must believe the patient's report of pain. How then do care givers in general, and emergency 
NURSES' ATTITUDES

nurses in specific, appropriately and accurately document the pain of those who present to the emergency department for the purpose of obtaining narcotics for non-medical use? Though much work has been done in the area of drug abuse, as well as related to treating patients' pain, little research has been done to explore emergency nurses' experiences with the population of patients casually referred to as drug-seekers. In order to develop a plan of action to deal with this misuse of both prescription drugs and emergency departments, the concept of the term “drug-seeker" must be better understood. By developing an understanding of how emergency nurses utilize this term and how they feel about this challenging patient population, better identification and management of this problem can be implemented.

\section{Literature Review}

The literature suggests that patients with a history of substance abuse will tend to be viewed as drug-seekers if they present to an emergency department with a chief complaint of pain. ${ }^{5}$ The concept of opiophobia, described as the clinician's fear of prescribing narcotics for the treatment of pain due to the fear of abuse, ${ }^{5}$ must be understood when treating this patient population. It is important to evaluate doctors' perceptions of patients' reporting of pain as well their experiences with opiophobia. ${ }^{6}$ Nurses are encouraged to utilize a patient-centered approach to pain management for patients who are in pain but have co-existing substance abuse problems. ${ }^{7}$ Nurses need to be educated about how to meet the patients' needs and also understand the complex psychological phenomena of addiction. They should also be aware of signs that can warn healthcare providers of drug-seeking activity including visiting the emergency department at night, losing prescriptions for narcotics, using fake names, refusing medications other than narcotics, and requesting medication by name and dose. ${ }^{7}$ 
NURSES' ATTITUDES

A policy, funded by a federal grant and implemented in Washington State, was explored. ${ }^{8}$ People presenting to emergency departments to obtain narcotics for non-medical use were being identified by health care providers and then referred to the state's Department of Social and Health Services (DSHS) for treatment of potential addiction. A survey was conducted by the DSHS of 8,100 prescription-seeking patients, and about half were identified through this program as potential addicts. This number was double what officials had anticipated. Programs like this have been implemented in other states in response to the misuse of prescription drugs. Several different management personnel from emergency departments around the country were asked how they deal with drug-seekers. ${ }^{9}$ One doctor suggested utilizing assessment skills and some detective work to attempt to differentiate drug-seekers versus patients in true pain. Another clinician interviewed suggested referring patients who frequently present to the emergency department seeking narcotics to the care manager in order to set up a care plan for pain management.

Limited research has been conducted in the area of caring for patients who are seeking drugs for non-medical use. It has been recommended that providers use the World Health Organization's (WHO) analgesic ladder advocating for use for all patients in pain, regardless of their drug addiction status. ${ }^{5}$ Nurses' perceptions of patients' pain are important to understand. In a review of pain management and barriers in the emergency department, nurses identified that they would determine how much pain they feel the patient is in rather than believe the patient's rating of their pain. This disconnect between patients' pain ratings and nurses' perception of patients' pain serves as a barrier to adequate pain management. ${ }^{11}$

A descriptive study surveyed 400 nurse practitioners (NPs) from around the country in an effort to determine knowledge and attitudes towards pain management. ${ }^{11}$ The authors found that 
NURSES' ATTITUDES

NPs would like to have a way to tell if patients are being honest about their report of pain, however no ethical way to provide this reassurance exists. Conclusions drawn from the study included that NPs found drug-seekers to be one of the greatest challenges to providing adequate pain management in the emergency department setting.

One of the only research studies that addressed nurses' experiences with drug-seekers was a descriptive study designed to explore and describe from the nurses' perspective the meaning of the term "drug seeking." 12 The study had four major focus areas including: identifying what behaviors patients labeled as drug seekers displayed; describing nurses' definitions of "drug seeking"; identifying how nurses respond to the use of this term in health care; and exploring any differences between general nurses, emergency nurses, and pain management nurses. Surveys were distributed and collected prior to nurses' attending a pain management conference. Nurse respondents believed that drug seekers tend to: go to many emergency departments to get pain medications; direct the nurse in the administration of the drug; have inconsistencies in their story; and say they lost their prescription for narcotics. Nurses defined drug seeking to mean patients were addicted to opioids, were abusing medications, and were manipulative in order to get their medications. The majority of nurses surveyed believed that the term "drug seeking" has a negative connotation. The study suggested that emergency nurses' responses were similar to those of nurses in general. However, emergency nurses were more likely to believe that patients were enjoying their doses of pain medication and also were more likely to call the patient's behavior "drug-seeking" than were pain management nurses. The study suggested that clinicians must treat patients' pain to be sure their behavior is not a result of under treatment of pain, and clinicians must also be careful to rule out physiological etiology of pain prior to referring to patients as "drug-seekers." 
NURSES' ATTITUDES

The literature clearly suggests a problem exists in emergency departments with the abuse of prescription drugs. Emergency nurses must treat patients in pain, and to remain ethical in practice they are obligated at the same time to identify the misuse of drugs. In order for emergency nurses to accomplish this, a deeper understanding of their experiences with the term “drug-seekers" must be achieved. In doing so, potential strategies to deal with drug-seekers could begin to be identified. Because scant literature exists that explores what emergency nurses mean when they refer to patients as "drug-seekers", the purpose of this study was to explore emergency nurses' definition of “drug-seekers" and also to examine their perceptions of and experiences with this patient population.

Azjen's Theory of Planned Behavior was used to guide this study. ${ }^{13}$ This theory proposes that a person's attitude, combined with subjective norms, leads the person to form intentions. These intentions serve as the basis for behavior. In this study, emergency nurses' beliefs about drug seekers, combined with the views of the other clinicians in the emergency department environment, potentially impact the care delivered to drug-seekers. By exploring emergency nurses' perceptions and experiences with drug-seekers, some suggestions about intentions and behavior could be proposed.

\section{Methods}

\section{Design}

This study utilized a descriptive survey design.

\section{Site and Sample}


NURSES' ATTITUDES

This study was conducted at a Level 1 trauma center located in an urban teaching hospital. The trauma center serves more than 100,000 patient visits per year and there are approximately 150 emergency nurses working in the adult setting. Any adult emergency nurse was eligible to voluntarily participate in the survey. The researcher sought to obtain a sample size of at least 100 nurses.

\section{Measurement}

Nurses' perceptions of drug seekers were measured with an adapted version of a survey entitled “Survey on Nurses' Perceptions of Drug Seekers and Their Definition of Drug Seekers". This survey was originally piloted, developed, and utilized by Ferrell, Grimm, McCaffery, Pasero, and Uman, and permission was obtained from the authors to use the survey. ${ }^{14}$ This survey contained two parts: Part A, which identifies patient behaviors that nurses associate with drug-seekers; and Part B which explores nurses' use of the term “drug-seeker.” In the original measure, Part A had a reported internal consistency of coefficient alpha of 0.90 , and part B questions one through five had a reported coefficient alpha of $0.83 .{ }^{14}$ Respondents had the opportunity to add additional comments at the end of each section.

The author developed five additional open-ended questions in order to give the respondent an opportunity to share personal beliefs about and experiences with drug-seekers. These questions were developed from the literature and clinical experience and were pilot tested on two nurses before used in the study. Demographic data were collected, including age, gender, years of experience as a health professional, and highest education.

\section{Procedures}


NURSES' ATTITUDES

This study was presented to and approved by the health care institution's and College's Institutional Review Boards (IRB). The researcher was also granted permission by management in the emergency department to conduct the survey. After IRB approval, an e-mail was sent to all emergency nurses in order to make them aware of the study and an IRB approved flyer was posted in the break room announcing the survey. The researcher then announced the project at multiple "roll calls," a time before the beginning of the shift when nurses gather in the break room for a 15-20 minute period. In addition to an informational letter that accompanied the survey and served as consent, the researcher made herself available by e-mail, phone, and in person for any questions participants may have had. Contact information was on the information page, in the e-mail, and on the flyer. Participation was voluntary and surveys were anonymous. Surveys were left in the break room, next to a locked collection box for a period of one month, so that participants would have access to the surveys whenever they might have time to complete them. No surveys were collected directly from respondents. Completed surveys were placed in the locked drop box that only the researcher had access to.

\section{Data Analysis}

Survey data were analyzed using SPSS version 21 software. Descriptive statistics were performed and frequency and percentages of survey data were calculated by item. The researcher analyzed qualitative data gathered from the open-ended questions by identifying common themes.

\section{Results}

Twenty-three emergency nurses responded to the survey, for a response rate of $15.3 \%$. Demographic data is summarized in Table 1. 


\begin{tabular}{|c|c|c|c|c|c|c|c|c|}
\hline Table 1. & & & Demogr & hic Dat & & & & \\
\hline Age & $\begin{array}{l}\mathbf{2 5 - 2 9} \\
21.7 \%\end{array}$ & $\begin{array}{l}\mathbf{3 0 - 3 4} \\
21.7 \%\end{array}$ & $\begin{array}{l}\mathbf{3 5 - 3 9} \\
17.4 \%\end{array}$ & $\begin{array}{l}40-44 \\
9.7 \%\end{array}$ & $\begin{array}{c}\mathbf{4 5 - 4 9} \\
0 \%\end{array}$ & $\begin{array}{l}\mathbf{5 0 - 5 4} \\
4.3 \%\end{array}$ & $\begin{array}{l}\mathbf{5 5 - 5 9} \\
21.7 \%\end{array}$ & $\begin{array}{c}\text { No } \\
\text { Response } \\
4.3 \%\end{array}$ \\
\hline $\begin{array}{c}\text { Years } \\
\text { Experience }\end{array}$ & $\begin{array}{l}\mathbf{0 - 4} \\
13 \%\end{array}$ & $\begin{array}{c}\mathbf{5 - 9} \\
26.1 \%\end{array}$ & $\begin{array}{l}\mathbf{1 0 - 1 4} \\
21.7 \%\end{array}$ & $\begin{array}{c}\mathbf{1 5 - 1 9} \\
13 \%\end{array}$ & $\begin{array}{c}\mathbf{2 0 - 2 4} \\
4.3 \%\end{array}$ & $\begin{array}{l}\mathbf{3 0 - 3 4} \\
4.3 \%\end{array}$ & $\begin{array}{c}\text { No } \\
\text { Response } \\
4.3 \%\end{array}$ & \\
\hline $\begin{array}{c}\text { Highest } \\
\text { Educational } \\
\text { Level }\end{array}$ & $\begin{array}{c}\text { Diploma } \\
4.3 \%\end{array}$ & $\begin{array}{c}\text { AD } \\
26.1 \%\end{array}$ & $\begin{array}{c}\text { BSN } \\
60.1 \%\end{array}$ & $\begin{array}{l}\text { MSN } \\
4.3 \%\end{array}$ & $\begin{array}{c}\text { Other } \\
4.3 \%\end{array}$ & & & \\
\hline
\end{tabular}

The majority of respondents were less than 40 years old, had 14 years or less of experience, and had a BSN.

Responses to individual survey items are summarized in Table 2. 


\section{Question}

A. How likely is it that the following behaviors may cause you to refer to a patient as drug seeking?

A1.Reports allergy to everything but a certain narcotic

A2. States the name and dose of narcotic that best relieves the pain

A3. Goes to different emergency

rooms/different physicians to get narcotics

A4. Prefers "needle" to the pill

A5. "Clock-watcher"

A6. Frequently comes to the same ER to get narcotics to relieve pain

A7. Enjoys his/her narcotic, e.g., happy, active, or talkative

A8. Tells nurse where to give drug or how fast

A9. Tells inconsistent stories about pain or medical history

A10. Asks for a refill because prescription was lost or stolen

B. When you refer to a patient as "drugseeking," how likely is it that you mean the following? What does it mean to you when others use it?

B1. Patient is addicted to narcotics

B2. Patient is lying about pain

B3. Patient is exaggerating pain

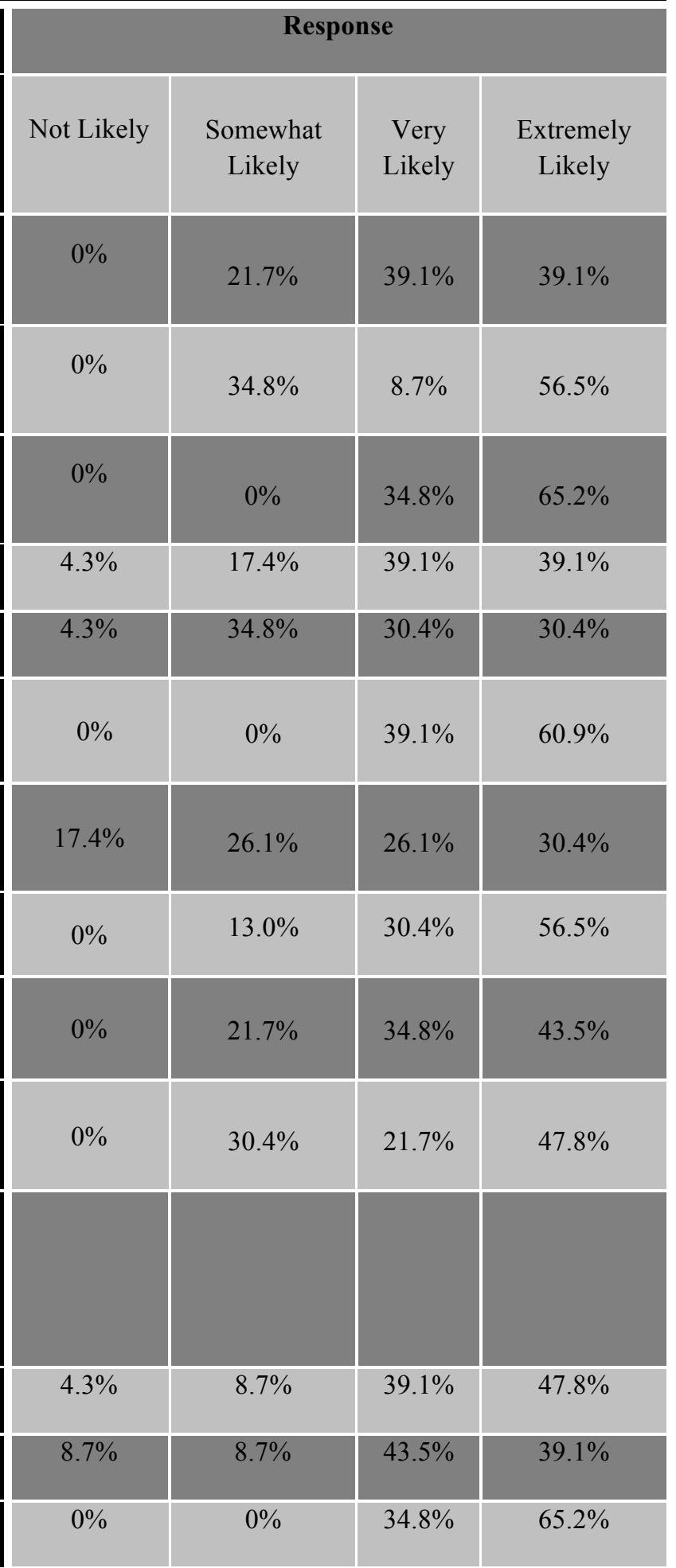


NURSES' ATTITUDES

B4. Patient is abusing pain medication

B5. Patient is manipulative

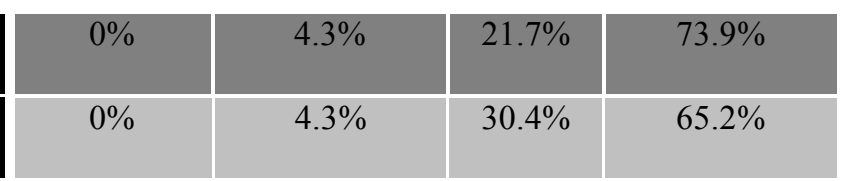

The survey responses indicate that certain key behaviors lead emergency nurses to refer

to patients as "drug-seeking." These behaviors include reporting allergies to all medications

except for certain narcotics, going to different emergency rooms to obtain narcotics, prefers

intravenous medications, frequently presents to the emergency room for narcotics, instructs the

nurse on how to administer the medication, and provides an inconsistent medical history. When

emergency nurses use the term "drug-seeking," the survey responses indicate they mean the

patient may be addicted to narcotics, could be exaggerating pain, is abusing pain medication, is

lying about pain, and is being manipulative.

When responding to the open ended questions, many common themes emerged (Table 3 ).

\section{Table 3. $\quad$ Responses to Open Ended Questions}

\begin{tabular}{|c|c|}
\hline $\begin{array}{l}\text { 1. Do you believe there is a problem } \\
\text { with "drug-seekers" in the ER? If yes, } \\
\text { what do you feel the problem is? }\end{array}$ & $\begin{array}{l}\text { Too many narcotics prescribed } \\
\text { Inconsistencies between providers } \\
\text { Lack of policies/knowledge of policies } \\
\text { around narcotics } \\
\text { No follow-up }\end{array}$ \\
\hline $\begin{array}{l}\text { 2. Do you feel that your peers treat } \\
\text { "drug-seekers" differently than other } \\
\text { patients? If yes, how do you feel they } \\
\text { treat these patients? }\end{array}$ & $\begin{array}{l}\text { Frustrated } \\
\text { Annoyed } \\
\text { Ignored } \\
\text { Less compassion given }\end{array}$ \\
\hline $\begin{array}{l}\text { 3. How do you feel about "drug- } \\
\text { seekers" and "drug-seeking" } \\
\text { behaviors? How does it impact your } \\
\text { personal job satisfaction? }\end{array}$ & $\begin{array}{l}\text { Waste time } \\
\text { Frustrates } \\
\text { Time consuming; takes away from other } \\
\text { patients } \\
\text { Waste of resources }\end{array}$ \\
\hline $\begin{array}{l}\text { 4. How do you feel about utilizing the } \\
\text { term "drug-seeking" in your charting? }\end{array}$ & $\begin{array}{l}\text { Don't use it } \\
\text { Wish I could use it } \\
\text { Don't know if it is legal } \\
\text { Document behaviors instead }\end{array}$ \\
\hline
\end{tabular}


NURSES' ATTITUDES

The responses to the open ended questions indicate that respondents believed there is a problem with drug-seeking patients in the emergency room. They identified a variety of facets to this problem including a lack of education about existing policies and consistent enforcement of these policies to handle this population. Emergency nurse respondents expressed frustration with this population, and indicated that these patients take both valuable time and resources from other patients. Most respondents indicated that they were uncomfortable using the term "drugseeking" in their charting; some expressed a desire to use the term while others used variations such as "drug-seeking behavior" as an alternative to labeling the patient as a drug-seeker in charting.

When asked what other behaviors emergency nurses considered "drug-seeking," many respondents indicated they believed that when a patient comes to the emergency department multiple times with the same complaint they are drug-seeking. Additionally, behavior inconsistent with reported pain level or behaviors that seemed overly "dramatic" were considered drug-seeking behaviors. When asked to describe other meanings of the term "drug-seeker," respondents indicated people who try to get narcotics to sell and a patient who self-medicates.

\section{Discussion}

In this study, many emergency nurses agreed that there is a problem with drug-seekers in the emergency room. Nurses agreed on what behaviors can be used to identify patients as drugseekers, and these were consistent with the existing literature. Many of these behaviors can be verified through computer charting, so for example an emergency nurse could easily verify if a patient had had multiple repeat visits for the same complaint. The nurses overwhelmingly 
NURSES' ATTITUDES

agreed on what they meant by "drug-seeking," responding that it meant a patient who misuses and manipulates emergency care to obtain narcotics and who abuses narcotic prescriptions.

Some respondents indicated that they did not feel adequately trained as to how to best care for this patient population. One potential strategy is to educate emergency nurses about the importance of accurately documenting these behaviors in the medical record. Identification of potential drug-seeking can provide the nurse with an opportunity to advocate for appropriate care for the patient and develop and discuss a plan of care with the ED provider that is more beneficial to the patient and more satisfactory to the ED team. Further research as to how to best manage this patient population is critically needed.

\section{Limitations}

The sample size was limited, and only $15 \%$ of potential subjects responded to the survey, thus limiting the ability to generalize to this emergency department or beyond. Yet valuable insights were gained and findings were consistent with what little information is available in the

literature. Respondents had similar demographic characteristics to RNs in the United States, ${ }^{\mathrm{I}}$ though males were over represented in this sample when compared to the national average. Data with regard to race and ethnicity was not collected, thus it is unknown if the sample is representative in this respect. Only emergency nurses were surveyed. Further research that includes all members of the interdisciplinary team responsible for both the prescription and administration of narcotics is recommended.

\section{Implications for Emergency Nurses}

Nurses in the emergency department, as the usual first providers of care, have a unique opportunity to potentially identify, advocate for, and participate in care planning and 
NURSES' ATTITUDES

implementation of strategies for patients who are potentially drug seeking. Advocacy is critically important as negative attitudes of providers have the potential to negatively impact care. Advanced practice nurses (APRNs) in the emergency department have the opportunity to play a unique role in formulating solutions to the problem of both misuse and misprescribing of narcotics in the emergency department setting. Educational programs can be developed and implemented by the APRN for all levels of care providers in the emergency department. APRNs must be mindful in their own prescribing practices and remain up to date on current best practices surrounding both correct prescribing of narcotics and proper identification of the potential misuse of prescribed narcotics. Emergency nurses and APRNs can serve as positive role models to other members of the team to assure that this practice is followed.

\section{Conclusions}

The responses to this survey support existing research that describes what providers mean when they describe patients as drug-seekers. Comprehensive documentation of drug-seeking behaviors is recommended to assist in identifying this pattern of behavior so that patients may then be referred to appropriate resources. Additionally, prescribers of narcotics should exercise caution to avoid misprescribing narcotics to those patients whose behavior is consistent with narcotic misuse. 


\section{References}

1. Niska, R., Bhuiya, F., \& Xu, J. (2010). National hospital ambulatory medical care survey: 2007 emergency department summary National health statistics reports 26. Retrieved from Centers for Disease Control website: http://www.cdc.gov/nchs/data/nhsr/nshr026.pdf

2. Cai, R., Crane, E., \& Poneleit, K. (2010). Emergency department visits involving nonmedical use of selected prescription drugs --- United States 2004-2008 Morbidity and Mortality Weekly Report, 59(23), 705-709. Retrieved from Centers for Disease Control website: http://cdc.gov/mmwr/preview/mmwrhtml/mm5923a1.htm?s_cid=mm5923a1_w

3. U.S. Department of Health and Human Services, National Institute of Health, National Institute on Drug Abuse. (2008). Prescription medications: Drug abuse and related topics. Retrieved from: http://www.drugabuse.gov/drugpages/prescription.html

4. The Joint Commission (2012, January). Facts about pain management. Accreditation, Health Care, Certification | Joint Commission. Retrieved October 20, 2012, from http://www.jointcommission.org/assets/1/18/Pain_Management.pdf

5. Kurtz, D. (2003). Managing acute pain in admitted or suspected substance abusers. Physician Assistant, 27(7), 36-44.

6. Ducharme, J. (2005). Clinical guidelines and policies: Can they improve emergency department pain management? Journal of Law, Medicine, \& Ethics, 783-790.

7. Finney, L. (2010). Nursing care for the patient with co-existing pain and substance misuse: Meeting the patient's needs. MEDSURG Nursing, 19(1), 25-53.

8. Scheck, A. (2005). Washington State at the forefront of deterring drug seekers. Emergency Medicine News, 27(5), 42-44. Retrieved from OVID database. (doi: 00132981-200505000-00038)

9. Zimmermann, P. G. (2005). Cutting-edge discussions of management, policy, and program issues in emergency care. Journal of Emergency Nursing, 31(1), 91-99.

10. Duignan, M., \& Dunn, V. (2008). Barriers to pain management in emergency departments. Emergency Nurse, 15(9), 30-34. 
NURSES' ATTITUDES

11. D'Arcy, Y. (2009). Be in the know about pain management. The Nurse Practitioner, $34(4), 43-47$.

12. Ferrell, B., Grimm, M., McCaffery, M., Pasero, C., \& Uman, G. (2005). On the meaning of "drug seeking." American Society for Pain Management Nursing, 122-136. doi: 10.1016/j.pmn.2005.08.002

13. Azjen, I. (1991). The theory of planned behavior. Organizational Behavior and Human Decision Processes, 50, 179-211. Retrieved from Webhosting at UMass Amherst website: http://people.umass.edu/psyc661/pdf/tpb.obhdp.pdf

14. Ferrell, B., Grimm, M., McCaffery, M., Pasero, C., \& Uman, G. (2005). On the meaning of "drug seeking." American Society for Pain Management Nursing, 122-136. doi: 10.1016/j.pmn.2005.08.002

15. U.S. Department of Health and Human Services, Health Resources and Services Administration. (2010). The registered nurse population. Retrieved from website: http://bhpr.hrsa.gov/healthworkforce/rnsurveys/rnsurveyfinal.pdf 
NURSES' ATTITUDES 